\title{
PENGARUH PELATIHAN BALUT BIDAI TERHADAP PENGETAHUAN PADA MAHASISWA/I KEPERAWATAN STIKES TRI MANDIRI SAKTI BENGKULU
}

\author{
Devi Listiana ${ }^{1}$, Yulita Elvira Silviani ${ }^{2}$ \\ Program Studi Ilmu Keperawatan, STIKES Tri Mandiri Sakti Bengkulu \\ devilistiana01@gmail.com', vivielvira92@gmail.com²
}

\begin{abstract}
Splint Dressing (Fixation) is a general treatment of extremity trauma or immobilization from the site of trauma such as splinting (spalk) to maintain the position of broken bones so as not to move and prevent contamination and complications. Formulation of problem in this study was whether there is Effect of Splint Dressing (Fixation) Training to Knowledge Students of Nursing at STIKES Tri Mandiri Sakti Bengkulu. The aims of this study was to determine Effect of Splint Dressing (Fixation) Training to Knowledge Students of Nursing at STIKES Tri Mandiri Sakti Bengkulu. This study used pre-eksperiment with one group pre-test post-test design. Population in this study were students of Nursing during 2020 with the amount of 126 students. Data analysis in this study used univariate and bivariate with Uji Wilcoxon Signed Rank Test.The results of this study showed: based on Wilcoxon Signed Rank Test obtained knowledge before treatment and after treatment were -8,347 with value of Asymp. Sig $(p)=0,000$. Because value of $p$-value $=0,000<0,05$ so that can be concluded there is Effect of Splint Dressing (Fixation) Training to Knowledge Students of Nursing at STIKES Tri Mandiri Sakti Bengkulu. It is expected that the STIKES Tri Mandiri Sakti Bengkulu can collaborate with PMI, Puskesmas, or the authorities regarding the first treatment of injuries so that they can assist students in making efforts to deal with students who are injured and respondents to increase knowledge through training, read material about splint splints through print media such as books on splint splints or electronic media.
\end{abstract}

Keywords: Splint Dressing (Fixation) Training, Skills

\begin{abstract}
ABSTRAK
Balut Bidai adalah perawatan umum trauma ekstremitas atau imobilisasi dari lokasi trauma seperti bidai (spalk) untuk mempertahankan posisi bagian tulang yang patah agar tidak bergerak dan mencegah terjadinya kontaminasi dan komplikasi. Rumusan masalah dalam penelitian ini adalah apakah ada pengaruh pelatihan balut bidai terhadap pengetahuan pada mahasiswa/i Keperawatan di STIKES Tri Mandiri Sakti Bengkulu. Tujuan penelitian ini adalah untuk mengetahui pengaruh pelatihan balut bidai terhadap pengetahuan pada mahasiswa/i Keperawatan di STIKES Tri Mandiri Sakti Bengkulu. Desain penelitian yang digunakan dalam penelitian ini adalah pre-eksperimental dengan menggunakan rancangan one group pre-test post-test design. Populasi penelitian ini adalah mahasiswa/i Keperawatan tahun 2020 sebanyak 126 orang. Teknik analisis data dilakukan dengan analisis univariat dan bivariat dengan Uji Wilcoxon Signed Rank Test. Hasil penelitian ini adalah berdasarkan Uji Wilcoxon Signed Rank Test didapat data pengetahuan sebelum perlakuan dan sesudah perlakuan sebesar $-8,347$ dengan nilai Asymp. Sig $(p)=0,000$. Karena nilai p-value $=0,000<0,05$ dengan demikian dapat disimpulkan bahwa ada pengaruh pelatihan balut bidai terhadap pengetahuan pada mahasiswa/i Keperawatan di STIKES Tri Mandiri Sakti Bengkulu. Diharapkan kepada pihak STIKES Tri Mandiri Sakti Bengkulu agar dapat bekerjasama dengan Palang Merah Indonesia (PMI) Provinsi Bengkulu, Puskesmas, ataupun pihak yang berwenang tentang penanganan pertama cedera sehingga dapat membantu mahasiswa/i dalam melakukan upaya penanganan terhadap mahasiswa/i yang mengalami cedera dan responden untuk meningkatkan pengetahuan melalui pelatihan, membaca materi tentang balut bidai melalui media cetak seperti buku tentang balut bidai atau media elektronik.
\end{abstract}

Kata Kunci : Pelatihan Balut Bidai, Pengetahuan 


\section{PENDAHULUAN}

Kondisi kegawatdaruratan dapat terjadi dimana saja dan kapan saja. Sudah menjadi tanggung jawab petugas kesehatan untuk menangani masalah tersebut. Namun tidak menutup kemungkinan kondisi kegawatdaruratan dapat terjadi pada daerah yang sulit dijangkau oleh petugas kesehatan. Sehingga pada kondisi tersebut peran serta masyarakat dan mahasiswa/i untuk membantu korban sebelum ditangani oleh petugas kesehatan menjadi sangat penting (Sudiharto \& Sartono, 2011).

Menurut World Health Organization (WHO), bencana adalah kejadian yang menyebabkan kerusakan, gangguan ekologis, hilangnya nyawa manusia, dan memburuknya derajat atau pelayanan kesehatan pada skala tertentu yang memerlukan respon dari masyarakat wilayah yang terkena bencana. Di dekade terakhir, menurut WHO 2007 jumlah total peristiwa bencana hampir dua kali lipat, menunjukkan garis trend dari sekitar 450 hingga 800 darurat besar per tahun. Peningkatan ini paling ditandai di negara berpenghasilan menengah dan rendah, di mana kesiapsiagaan darurat sering tidak mencukupi. Karena peningkatan kesiapsiagaan di banyak negara, lebih sedikit orang meninggal karena peristiwa bencana, tetapi jumlah orang yang terkena dampaknya masih meningkat, dengan jangka panjang yang penting implikasi. WHO akan bermitra dengan PBB Internasional Strategi untuk Pengurangan Bencana (ISDR) dan badan-badan PBB dan non-PBB lainnya pada 2008-2009 Safe Hospitals Initiative, yang bertujuan membangun ketahanan rumah sakit dan kesehatan lainnya fasilitas untuk bencana, baik struktural dan fungsional, sehingga mereka akan tetap berfungsi di bawah situasi darurat. Bukan hanya bencana alam yang terjadi, menurut WHO 2013 diperkirakan $70 \%$ kecelakaan lalu lintas di alami oleh pelajar/mahasiswa. Organisasi kesehatan dunia WHO mencatat 1,2 juta orang meninggal setiap tahunnya dalam kecelakaan lalu lintas dan 50 juta orang korban kecelakaan lalu lintas mengalami luka serius maupun cacat tetap.

Menurut data dari Badan Nasional Penanggulangan Bencana (BNPB) di Indonesia tahun 2018 jumlah kejadian bencana alam paling besar puting beliung yang terjadi di Jawa Tengah dengan jumlah 333 kali kejadian, di susul banjir di daerah Jawa Timur dengan jumlah 199 kali kejadian, dan yang terakhir tanah longsor di Jawa Barat dengan jumlah kejadian 175 kali.

Menurut Badan Nasional Penanggulangan Bencana (BNPB) tahun 2018 dari data 3 tahun terakhir di Bengkulu untuk kejadian bencana pada tahun 2016 sering terjadi tanah longsor dengan jumlah kejadian 7 kali, puting beliung dengan jumlah kejadian 5 kali, banjir dengan jumlah kejadian 5 kali, dan gempa dengan kejadian 1 kali. Pada tahun 2017 data bencana yang sering terjadi di Bengkulu banjir dengan jumlah kejadian 5 kali, gempa bumi dengan jumlah kejadian 2 kali, tanah longsor dengan jumlah kejadian 1 kali. Sedangkan pada tahun 2018 ini sering terjadi banjir di Provinsi Rejang Lebong jumlah kejadian 3 kali dan tanah longsor yang terjadi di Seluma dan Kepahiang dengan jumlah kejadian 1 kali. Bengkulu merupakan wilayah rawan gempa bumi dan tsunami karena wilayah Bengkulu terletak pada pertemuan lempeng tektonik IndoAustralia dan Eurasia yang merupakan generator utama aktivitas gempa bumi dan garis pantai dengan panjang lebih kurang $512 \mathrm{Km}$. Bengkulu wilayah rawan longsor karena berhadapan dengan bukit barisan dengan tingkat kelerengan di atas 60 derajat. Bengkulu wilayah rawan banjir karena panjang sungai di Bengkulu ratarata $86 \mathrm{~km}$ dengan hulu sungai berada pada 
kawasan bukit barisan. Bengkulu wilayah rawan polusi udara karena kebakaran hutan.

Kejadian bencana yang pernah terjadi di STIKES Tri Mandiri Sakti Bengkulu adalah gempa bumi yang membuat beberapa orang cedera ringan. Selain bencana alam juga terjadi cedera yang dialami mahasiswa/i akibat cedera aktifitas olahraga bola basket dan bola kaki sekitar 24,2\% dan cedera akibat terjatuh di sekolah sekitar 28,6\%. Cedera pada mahasiswa/i di lingkungan Perguruan Tinggi umumnya terjadi pada sistem muskuloskeletal yaitu tendon, otot, ligamen, kulit dan tulang. Kecelakaan pada sistem muskuloskeletal harus ditangani dengan cepat dan tepat. Tidak banyak penanganan yang bisa dilakukan oleh pihak perguruan Tinggi dan langsung membawa mahasiswa/i yang cedera ke rumah sakit terdekat. Jika tidak ditangani dengan cepat akan menimbulkan cedera yang semakin parah dan dapat memicu terjadinya pendarahan. Dampak lain yang terjadi dapat mengakibatkan kelainan bentuk tulang atau kecacatan bahkan kematian. Untuk mencegah terjadinya cedera pada sistem muskuloskeletal dibutuhkan pertolongan balut bidai melalui pendidikan (Thygerson, 2011).

Pengetahuan sendiri dipengaruhi oleh banyak faktor seperti pendidikan, umur, lingkungan, dan sosial budaya (Notoatmodjo, 2012). Tingkat pendidikan memiliki hubungan dengan tingkat pengetahuan, dimana tingkat pendidikan mampu mempengaruhi tingkat pengetahuan seseorang. Hubungan ini diharapkan semakin tinggi tingkat pendidikan seseorang maka semakin tinggi tingkat pengetahuannya. Pendidikan kesehatan merupakan usaha atau kegiatan untuk membantu individu, kelompok, dan masyarakat dalam meningkatkan kemampuan baik pengetahuan, sikap, maupun keterampilan untuk mencapai hidup sehat secara optimal (Notoatmodjo, 2012), bahkan dengan mewajibkan semua mahasiswa/i mendapatkan pendidikan pertolongan pertama sebelum lulus Perguruan Tinggi, maka kita dapat memastikan bahwa dalam dua generasi yang akan datang, tiap orang di tempat kecelakaan atau pada penyakit akut akan lebih sanggup menyelamatkan nyawa dan ekstremitas sampai tiba bantuan profesional (Boswick, 2012).

Balut bidai merupakan tindakan memfiksasi atau mengimobilisasi bagian tubuh yang mengalami cedera yang menggunakan benda yang bersifat kaku maupun fleksibel sebagai fiksator /imobilisasi. Kecelakaan merupakan kejadian yang tidak bisa diprediksi bahkan banyak kejadian kecelakaan terjadi di sekitar kita, dikalangan masyarakat bahkan dikalangan mahasiswa/i yang merupakan kawasan yang banyak orang, tetapi orang di sekitar kejadian tidak tahu harus berbuat pertolongan seperti apa sehingga terkadang hanya dibiarkan begitu saja sehingga peneliti tertarik memberikan pendidikan kesehatan (pelatihan) untuk menambah pengetahuan dan keberanian dalam melakukan pertolongan. Pertolongan balut bidai dapat dilakukan oleh semua orang awam yang terlatih. Salah satu orang awam yang telatih di Perguruan Tinggi adalah mahasiswa/i yang telah mendapatkan pendidikan dasar kegawatdaruratan.

Melalui pelatihan balut bidai diharapkan mahasiswa/i mampu meningkatkan pengetahuan tentang balut bidai, sehingga mahasiswa/i dapat membantu temannya yang terluka atau fraktur.

Rumusan masalah dalam penelitian ini adalah "apakah ada pengaruh pelatihan balut bidai terhadap pengetahuan pada mahasiswa/i Keperawatan di STIKES Tri Mandiri Sakti Bengkulu?". Tujuan penelitian ini adalah untuk mengetahui pengaruh pelatihan balut bidai terhadap pengetahuan pada mahasiswa/i Keperawatan di STIKES Tri Mandiri Sakti Bengkulu. 


\section{METODE}

Penelitian ini dilakukan pada bulan 31 Agustus-10 September 2020 di STIKES Tri Mandiri Sakti Bengkulu. Penelitian ini merupakan penelitian kuantitatif dengan menggunakan penelitian pre eksperimental dengan rancangan One Group Pre-test and Post-test design. Populasi dalam penelitian ini yaitu mahasiswa/i Keperawatan Semester II dan IV di STIKES Tri Mandiri Sakti Bengkulu.

Teknik pengambilan sampel pada penelitian ini adalah Total Sampling. Total sampling adalah teknik pengambilan sampel dimana jumlah sampel sama dengan populasi, berjumlah 126 orang. Dari 126 mahasiswa/i Keperawatan Semester II dan IV dipilih berdasarkan kriteria. Teknik pengumpulan data yang digunakan dalam penelitian ini adalah dengan menggunakan data primer. Data awal yang dikumpulkan dengan melakukan pengisian kuesioner dan lembar observasi, untuk mendapatkan tingkat pengetahuan balut bidai sebelum diberikan pelatihan balut bidai. Selanjutnya responden dibagikan modul tentang materi balut bidai serta video tentang balut bidai, kemudian diberikan pelatihan balut bidai sehari 2 jam selama 2 kali pertemuan yang disampaikan oleh narasumber pelatihan. Sesudah pelatihan data akhir diambil dengan kuesioner dan lembar observasi post test yang sudah disediakan.

\section{HASIL PENELITIAN}

\section{Analisis Univariat}

Analisis ini dilakukan untuk mendapatkan gambaran masing-masing variabel yang diteliti, baik variabel independen maupun variabel dependen. Hasil analisis univariat dapat dilihat pada tabel-tabel berikut :
Tabel 1. Distribusi Frekuensi Berdasarkan Jenis Kelamin Mahasiswa/i STIKES Tri Mandiri Sakti Bengkulu

\begin{tabular}{clcc}
\hline No. & Jenis Kelamin & Jumlah & $\begin{array}{c}\text { Persentase } \\
(\%)\end{array}$ \\
\hline 1 & Perempuan & 107 & 85 \\
\hline 2 & Laki-laki & 19 & 15 \\
\hline & Total & $\mathbf{1 2 6}$ & $\mathbf{1 0 0}$ \\
\hline
\end{tabular}

Berdasarkan tabel 1 diatas dapat diketahui bahwa sebagian besar responden adalah perempuan yaitu sebanyak 107 orang $(85 \%)$ serta laki - laki sebanyak 19 orang $(15 \%)$.

Tabel 2. Distribusi Frekuensi Berdasarkan Tingkat Pengetahuan Sebelum Perlakuan Mahasiswa/i di STIKES Tri Mandiri Sakti Bengkulu

\begin{tabular}{clcc}
\hline No. & $\begin{array}{c}\text { Tingkat } \\
\text { Pengetahuan }\end{array}$ & Frekuensi & $\begin{array}{c}\text { Persentase } \\
(\%)\end{array}$ \\
\hline 1 & Baik & 15 & 11,9 \\
\hline 2 & Cukup & 44 & 34,9 \\
\hline 3 & Kurang & 67 & 53,2 \\
\hline & Total & $\mathbf{1 2 6}$ & $\mathbf{1 0 0}$ \\
\hline
\end{tabular}

Dari tabel 2 diatas dapat diketahui: 15 orang $(11,9 \%)$ pengetahuan sebelum perlakuan baik, 44 orang $(34,9 \%)$ pengetahuan sebelum perlakuan cukup, 67 orang $(53,2 \%)$ pengetahuan sebelum perlakuan kurang.

Tabel 3. Distribusi Frekuensi Berdasarkan Tingkat Pengetahuan Sesudah Perlakuan Di STIKES Tri Mandiri Sakti Bengkulu

\begin{tabular}{clcc}
\hline No. & $\begin{array}{c}\text { Tingkat } \\
\text { Pengetahuan }\end{array}$ & Frekuensi & Persentase (\%) \\
\hline 1 & Baik & 70 & 55,6 \\
\hline 2 & Cukup & 32 & 25,4 \\
\hline 3 & Kurang & 24 & 19,0 \\
\hline & Total & $\mathbf{1 2 6}$ & $\mathbf{1 0 0}$ \\
\hline
\end{tabular}

Dari tabel 3 diatas dapat diketahui: 70 orang $(55,6 \%)$ pengetahuan sesudah perlakuan baik, 32 orang $(25,4 \%)$ pengetahuan sesudah perlakuan cukup, 24 
orang $(19,0 \%)$ pengetahuan sesudah perlakuan kurang.

\section{Analisis Bivariat}

Analisis ini dilakukan untuk mengetahui pengaruh antara variabel independen (pelatihan balut bidai) dan variabel dependen (pengetahuan yaitu menggunakan uji Wilcoxon Sign Rank Test.

Tabel 4. Uji Wilcoxon Sign Rank Test

\begin{tabular}{lllllll}
\hline & & $\mathrm{N}$ & $\begin{array}{c}\text { Mean } \\
\text { Rank }\end{array}$ & $\begin{array}{c}\text { Sum of } \\
\text { Ranks }\end{array}$ & $\mathrm{Z}$ & $\mathrm{P}$ \\
\hline $\begin{array}{l}\text { Pengetahuan } \\
\text { Sesudah- } \\
\begin{array}{l}\text { Pengetahuan } \\
\text { Sebelum }\end{array}\end{array}$ & Negative Ranks & $8^{\mathrm{a}}$ & 12.00 & 96.00 & & \\
\cline { 2 - 7 } & Positive Ranks & $91^{\mathrm{b}}$ & 53.34 & 4854.00 & -8.347 & .000 \\
\cline { 2 - 7 } & Ties & $27^{\mathrm{c}}$ & & & & \\
\cline { 2 - 6 } & Total & 126 & & & & \\
\hline
\end{tabular}

Uji Wilcoxon Sign Rank Test pada responden yaitu terdapat pengaruh yang signifikan dimana nilai P-Value $=0,000<$ 0,05 , berarti terdapat perbedaan pengetahuan tentang balut bidai pada mahasiswa/i sebelum dan sesudah pelatihan, yang berarti Ho ditolak dan $\mathrm{Ha}$ diterima. Jadi, ada pengaruh pelatihan balut bidai terhadap pengetahuan pada mahasiswa/i keperawatan di STIKES Tri Mandiri Sakti Bengkulu.

\section{PEMBAHASAN}

Hasil analisis ini didapatkan data sebelum perlakuan balut bidai (pretest) terdapat 15 orang $(11,9 \%)$ pengetahuan sebelum perlakuan baik, 44 orang $(34,9 \%)$ pengetahuan sebelum perlakuan cukup, 67 orang $(53,2 \%)$ pengetahuan sebelum perlakuan kurang.

Hasil pretest menunjukkan bahwa sebelum diberikan pelatihan balut bidai pengetahuan responden masih dalam kategori kurang. Responden yang berpengetahuan baik terdapat 15 orang, hal ini dikarenakan 10 orang mahasiswa/i sebelumnya adalah anggota PMR (Palang Merah Remaja) sewaktu duduk dibangku Sekolah Menengah Atas (SMA) dan 5 orang mahasiswa/i adalah anggota Perawat Siaga Bencana (Perwagana), sehingga sudah mendapatkan materi balut bidai. Responden yang berpengetahuan cukup terdapat 44 orang, hal ini disebabkan kurang informasi tentang balut bidai dan kurang aktifnya mengikuti ekstrakulikuler PMR sebelum masuk ke Perguruan Tinggi, sedangkan responden yang berpengetahuan kurang terdapat 67 orang hal ini disebabkan sebagian mahasiswa/i banyak yang belum mendapatkan informasi mengenai balut bidai, masih banyak mahasiswa/i yang tidak pernah mengikuti ekstrakurikuler PMR sebelum memasuki Perguruan Tinggi dan tidak mengikuti ekstrakurikuler Perawat Siaga Bencana (Perwagana) ketika masuk Perguruan Tinggi. Informasi merupakan suatu data yang diperoleh dari suatu kejadian dan kemudian diubah menjadi bentuk yang dapat berguna dan memiliki arti bagi penerima informasi dimana fungsi utama informasi sendiri untuk meningkatkan pengetahuan. Pengalaman adalah mampu memperluas pengetahuan seseorang, yang mampu meningkatkan pengetahuan seseorang baik pengalaman yang didapatkan secara positif maupun negatif (Notoatmodjo, 2010).

Hasil analisis tingkat pengetahuan mahasiswa/i STIKES Tri Mandiri Sakti Bengkulu sesudah diberikan pelatihan balut bidai selama $2 \mathrm{x}$ pertemuan (posttest) didapatkan 70 orang $(55,6 \%)$ pengetahuan sesudah perlakuan baik, 32 orang $(25,4 \%)$ pengetahuan sesudah perlakuan cukup, 24 orang $(19,0 \%)$ pengetahuan sesudah perlakuan kurang. Dari hasil posttest 
menunjukkan bahwa sesudah diberikan pelatihan balut bidai pengetahuan responden dalam kategori baik dengan jumlah 70 orang $(55,6 \%)$ hal ini dikarenakan mahasiswa/i sudah banyak mendapatkan informasi mengenai balut bidai dari materi dan pelatihan yang diberikan.

Responden yang berpengetahuan cukup terdapat 32 orang mengalami peningkatan sebelum diberikan materi balut bidai dari kategori kurang ke cukup dengan jumlah 20 orang, 12 orang masih didalam kategori cukup, sedangkan terdapat 24 orang yang dikategorikan kurang, hal ini disebabkan karena kurang aktifnya responden untuk mencari informasi lagi dan bertanya ke narasumber saat diberi materi balut bidai. Terdapat peningkatan antara sebelum dan sesudah dilakukan pelatihan balut bidai.

Pengetahuan merupakan hasil tahu yang terjadi setelah seseorang melakukan penginderaan pada suatu objek melalui pancaindera manusia (Nursalam dan Effendi (2008). Tingkat pengetahuan balut bidai pada responden dalam penelitian ini adalah pada tingkat tahu (Know) dan memahami (Comprehension). Tahu adalah ingatan yang sudah ada sebelumnya setelah mengamati suatu objek namun masih kurang diinterpretasikan dalam kehidupan seharihari. Memahami merupakan suatu sikap yang tidak hanya tahu namun juga mampu menginterpretasikan suatu objek dengan benar (Notoatmodjo, 2010). Menurut Notoatmodjo (2010) faktor-faktor yang mempengaruhi pengetahuan adalah informasi merupakan suatu data yang diperoleh dari suatu kejadian dan kemudian diubah menjadi bentuk yang dapat berguna dan memiliki arti bagi penerima informasi dimana fungsi utama informasi sendiri untuk meningkatkan pengetahuan. Pengalaman mampu memperluas pengetahuan seseorang, yang mampu meningkatkan pengetahuan seseorang baik pengalaman yang didapatkan secara positif maupun negatif.

Sehingga penelitian ini sesuai dengan penelitian sebelumnya yang dilakukan oleh Sari Dwi (2015), didapatkan hasil pengumpulan data setelah dilakukan pelatihan balut bidai terdapat peningkatan pengetahuan dapat dilihat sebelum pelatihan $6,7 \%$ pengetahuan baik menjadi $66,7 \%$ dan penurunan pengetahuan yang rendah dari $43,3 \%$ menjadi $10,0 \%$ dan menurut penelitian Warouw Jessicha (2018), berdasarkan data pengetahuan tersebut, maka disimpulkan hasil penelitian menunjukkan bahwa tingkat pengetahuan responden sesudah diberikan pendidikan kesehatan yaitu 16 siswa $(100 \%)$ berada pada kategori baik, ada perbedaan antara sebelum dan sesudah dilakukan pendidikan kesehatan tentang balut bidai terhadap peningkatan pengetahuan dan keterampilan Siswa kelas X SMK Negeri 6 Manado.

Peneliti berpendapat adanya peningkatan pengetahuan ini sesungguhnya tidak lepas dari pemberian pelatihan. Pelatihan diberikan dengan motode ceramah dan tanya jawab serta membagikan modul yang berisi tentang materi balut bidai. Pemberian teori dan modul dimaksudkan dapat memberikan pengetahuan dan informasi yang lebih banyak. Sehingga tingkat pengetahuan menunjukkan adanya perubahan sesudah diberikan pelatihan.

Pengaruh pelatihan balut bidai terhadap pengetahuan, menggunakan uji Wilcoxon Signed Ranks Test yang menunjukan hasil nilai pada pengetahuan terdapat Negative Rank sebanyak 8 dan Mean Rank $=12,00$ serta Sum of Ranks $=96,00$ yang artinya terdapat penurunan rank sebanyak delapan orang, rank rata-rata $=12,00$ dan jumlah ranking=96,00. Positive Ranks=91, Mean Ranks=53,34 dan Sum of Ranks=4854 yang artinya terdapat peningkatan rank 
sebanyak 91, rank rata-rata $=53,34$ dan jumlah dari rank setelah perlakuan $=4854$.

Hasil penelitian ini berdasarkan $U j i$ Wilcoxon Signed Rank Test didapat data pengetahuan sebelum perlakukan dan sesudah perlakuan sebesar -8,347 dengan nilai Asymp. Sig (p) $=0,000$, Karena nilai $\mathrm{p}$-value $=0,000<0,05$ dengan demikian dapat disimpulkan bahwa ada pengaruh pelatihan balut bidai terhadap pengetahuan mahasiswa/i Keperawatan di STIKES Tri Mandiri Sakti Bengkulu.

Hal itu disebabkan oleh kemampuan mahasiswa/i dalam mengingat dan memahami materi balut bidai berbedabeda. Meningkatnya pengetahuan seseorang dibutuhkan pemahaman untuk menjelaskan kembali tentang informasi yang diperoleh. Mengingat dan memahami merupakan dimensi penting dalam proses pembelajaran. Adanya tingkat pengetahuan balut bidai tidak lepas dari pemberian pelatihan. Pelatihan diberikan dengan metode ceramah dan tanya jawab serta membagikan modul tentang materi balut bidai serta video tentang balut bidai.

Pengetahuan diartikan sebagai kemampuan untuk mengingat suatu materi yang telah diberikan sebelumnya. Untuk mengukur bahwa seseorang dikatakan tahu terhadap apa yang pernah dipelajari adalah dengan melihat kemampuan menyebut, menguraikan, mendefinisikan, menyatakan dan lain sebagainya (Notoadmodjo, 2010). Pengetahuan dasar dan pemahaman tentang balut bidai sangat penting bagi individu untuk dapat memberikan perawatan darurat jika terjadi bencana atau kecelakaan, boleh jadi dapat menyelamatkan nyawa dan meminimalisir adanya cedera. Semakin baik pengetahuan seseorang maka tindakan yang dilakukan akan semakin tertata atau terorganisir (Nursalam \& Efendi, 2008).

Didukung dengan hasil penelitian sebelumnya menurut Sari Dwi (2015) menunjukkan perbedaan tingkat pengetahuan sebelum dan sesudah diberikan pelatihan. Sesudah diberikan pelatihan pengetahuan siswa mengalami peningkatan $66,7 \%$ dengan pengetahuan baik. Nilai rata-ratanya mengalami peningkatan 15,10 dan nilai standar deviasi sebelum diberikan pelatihan 3,60 sesudah diberikan pelatihan dengan nilai standar deviasi 4,43, dan penelitian menurut Warouw Jessicha (2018), juga dapat dilihat bahwa terdapat perbedaan yang signifikan antara nilai rata-rata sebelum diberikan pendidikan kesehatan dan nilai rata-rata sesudah diberikan pendidikan kesehatan dimana nilai ratarata sesudah diberikan pendidikan kesehatan $(62,19)$ lebih tinggi dibandingkan nilai rata-rata sebelum diberikan pendidikan kesehatan $(44,6)$, dapat disimpulkan bahwa terdapat pengaruh yang signifikan pemberian pendidikan kesehatan terhadap tingkat pengetahuan tentang balut bidai pertolongan pertama fraktur tulang Panjang pada siswa kelas X SMK Negeri 6 Manado, maka Ho ditolak Ha diterima.

Dari hasil penelitian ini menunjukan ada pengaruh pelatihan balut bidai terhadap pengetahuan pada mahasiswa/i keperawatan. Oleh karena itu diharapkan kepada STIKES Tri Mandiri Sakti Bengkulu agar mampu bekerjasama dengan Palang Merah Indonesia (PMI), Puskesmas, ataupun pihak yang berwenang tentang penanganan pertama cedera sehingga dapat membantu mahasiswa/i dalam melakukan upaya penanganan terhadap mahasiswa/i yang mengalami cedera. Diharapkan juga pihak STIKES Tri Mandiri Sakti Bengkulu untuk melakukan pelatihan balut bidai agar dapat meningkatkan pengetahuan mahasiswa/I tentang pentingnya penanganan pertama, misalnya diadakan pelatihan 2 kali seminggu khususnya tentang balut bidai, sehingga mereka bisa menerapkan pengetahuannya di 
lingkungan Perguruan Tinggi maupun di masyarakat. Untuk menambah pengetahuan mahasiswa/i Keperawatan tentang balut bidai, dan bisa mengadakan pelatihan balut bidai dan bekerjasama dengan Palang Merah Indonesia (PMI), menambahkan pengetahuan melalui bukubuku dan media elektronik tentang balut bidai.

Implikasi keperawatan penelitian ini terhadap institusi pendidikan keperawatan dapat dijadikan sebagai sumber informasi tambahan mengenai peran dan fungsi perawat di Perguruan Tinggi, yang bermanfaat dalam pembelajaran mahasiswa/i Keperawatan. Para perawat perlu mengetahui dan memahami peran dan fungsinya agar dapat mengaplikasikannya. Peran dan fungsi keperawatan tidak hanya dapat dilakukan dirumah sakit akan tetapi perawat tetap bisa menjalankan peran dan fungsinya sebagai perawat di Perguruan Tinggi.

Hasil penelitian ini memperlihatkan bahwa ada pengaruh pelatihan balut bidai terhadap pengetahuan pada mahasiswa/i keperawatan di STIKES Tri Mandiri Sakti Bengkulu.

\section{KESIMPULAN}

Hasil tingkat pengetahuan mahasiswa/i Keperawatan tentang balut bidai sebelum diberikan 67 orang dengan persentase tertinggi $(53,2 \%)$ pengetahuan sebelum perlakuan kurang. Hasil tingkat pengetahuan mahasiswa/i Keperawatan tentang balut bidai sesudah diberikan perlakuan yaitu 70 orang $(55,6 \%)$ pengetahuan sesudah perlakuan baik. Ada pengaruh pelatihan balut bidai terhadap pengetahuan mahasiswa/i Keperawatan di STIKES Tri Mandiri Sakti Bengkulu.

\section{DAFTAR PUSTAKA}

BNPB. 2018. Data \& Informasi Bencana Indonesia.

(Online),
(http://dibi.bnpb.go.id/DesInventar/s howdatacard.jsp? clave $=2900 \& n S t a r$ $\mathrm{t}=0$, Diakses tanggal 15 September 2019).

Boswick. (2012). Perawatan Gawat Darurat (Emergency Care). Terjemahan oleh Sukwan Handali. 1997. Jakarta: EGC.

Notoatmodjo, S. (2007). Promosi Kesehatan dan Ilmu Perilaku. Jakarta: Rineka Cipta.

Nursalam \& Efendi, F (2008). Pendidikan Dalam Keperawatan. Jakarta : Salemba Medika.

Sari, Dwi. (2015). Pengaruh Pelatihan Balut Bidai Terhadap Pengetahuan dan Keterampilan Siswa Kelas di SMA Negeri 2 Seleman Yogyakarta. Diakses 10 Desember 2018 Pukul 21.00 WIB.

Sudiharto \& Sartono. (2011). Basic Trauma Cardiac Life Support. Jakarta: CV Sagung Seto.

Thygerson, Alton. (2011). First Aid: Pertolongan Pertama Edisi Kelima. Jakarta: Penerbit Erlangga.

Warouw, J.A, Kumat, L.T \& Pondaag. (2018). Pengaruh Pendidikan Kesehatan Dan Simulasi Terhadap Pengetahuan Tentang Balut Bidai Pertolongan Pertama Fraktur Tulang Panjang Pada Siswa Kelas X SMK Negeri 6 Manado. Diakses 10 Desember 2018 Pukul 21.00 WIB.

WHO, 2007. Risk Reduction and Emergency Preparedness. Printed by the WHO Document Production Service, Geneva, Switzerland. 
Diakses 10 Desember 2018 Pukul 21.00 WIB.

(2010). Metodologi

Penelitian Kesehatan. Jakarta:

Rineka Cipta.
(2012). Promosi Kesehatan dan Perilaku Kesehatan. Jakarta: Rineka Cipta. 